\title{
Burocratas da linha de frente: executores e fazedores das políticas públicas
}

\author{
Antonio Oliveira \\ Universidade Federal da Bahia
}

\begin{abstract}
A relação entre implementação das políticas, organização e burocracia é relevante porque ela ilumina a face de um problema crucial: o porquê de políticas serem bem-sucedidas ou fracassarem. As análises dessa relação indicam que o poder discricionário dos burocratas do nível da rua é um fator decisivo na distribuição de bens e serviços públicos; portanto, a ação desses agentes é uma variável relevante para o sucesso das políticas. Este artigo pretende discutir a discricionariedade dos burocratas do baixo escalão na aplicação das políticas públicas, usando como referência os argumentos apresentados na literatura especializada da implementação, da burocracia e da organização. A conclusão assinala questões que são importantes para o controle do poder discricionário dos agentes públicos, sublinhando que essa discrição é condição necessária à execução das políticas, mas que ela ameaça a accountability e a responsiveness.
\end{abstract}

Palavras-chave: implementação de políticas; burocracia da linha de frente; accountability; resposiveness; discricionariedade.

Los burócratas de la línea de frente: ejecutores y los responsables de las políticas públicas La relación entre la ejecución de la política pública, la organización y la burocracia es importante porque ilumina un problema crucial: porqué las políticas tienen éxito o fallan. Los análisis de esta relación indican que la discreción de los burócratas del nível de la calle es un factor crucial en la ejecución de los servicios públicos; por lo tanto la acción de estos agentes es importante para el éxito de la política pública. Este artículo discute la discreción de los burócratas del nível de la calle en la ejecución de la política pública y examina las discusiones en la literatura especializada: ejecución de la política pública, burocracia, organización. La conclusión señala las preguntas que son importantes para el control de la discreción de los agentes, subrayando que esta discreción es condición necesaria a la ejecución de la política pública, pero que él amenaza la accountability y la responsiveness.

Palabras clave: ejecución de la política pública; burocracia del nível de la calle; accountability; responsiveness; discreción.

"Artigo recebido em 16 out. 2011 e aceito em 12 jul. 2012. 
Street-level bureaucrats: implementers and makers of public policies

The relation between policy implementation, organization and bureaucracy is relevant because it illuminates the face of a crucial problem: why the policies have success or fail. The analyses of this relation indicate that the discretion of the street-level bureaucrats is a decisive factor in the delivery of the public goods and public services; therefore the action of these agents is important for the success of the policies. This article intends to discuss the discretion of the street-level bureaucrats in the application of the public policy and examines the presented arguments in the specialized literature: implementation, bureaucracy, organization. The conclusion indicates questions that are important to the control of the discretionary power of the public agents, underlining that this discretion is necessary condition to the application of the policies, but that it threat the accountability and the responsiveness.

KEY WORDs: policy implementation; street-level bureaucracies; accountability; responsiveness; discretion.

\section{Introdução}

A relação entre implementação das políticas, organização e burocracia é relevante para o debate acadêmico e público porque ela ilumina a face de um problema crucial: o porquê de políticas serem bem-sucedidas ou fracassarem. As análises desta relação indicam que o poder discricionário dos burocratas do nível da rua é decisivo na distribuição de bens e serviços públicos; portanto, a ação desses agentes é uma variável relevante para o sucesso das políticas. A discrição do burocrata da base é um importante tema para a gestão pública, porque a qualidade e a quantidade dos serviços prestados dependem dela, logo os esforços para compreenderem-se seus determinantes e consequências deveriam ser um objetivo relevante nas pesquisas da administração pública.

Este artigo discute a discricionariedade dos burocratas do baixo escalão na aplicação das políticas públicas, usando como referência os argumentos apresentados na literatura especializada da implementação, da burocracia e da organização. Essa literatura mostra que a análise da discricionariedade dos burocratas do nível da rua não pode deixar de lado as ambiguidades e imprecisões dos objetivos das políticas públicas, e esse tema é debatido no primeiro item. Na segunda seção, discutem-se a monitoração dos burocratas da linha de frente e os empecilhos a ela, destacando-se as controvérsias sobre a eficiência do emprego de incentivos para promover a regulação. Na terceira, analisam-se algumas características da organização policial e as falas de oficiais policiais militares da Bahia para ilustrarem os argumentos apresentados nos tópicos anteriores acerca das dificuldades no controle de burocratas que executam seus misteres na ponta do sistema. A conclusão assinala questões que são importantes para o controle do poder discricionário dos agentes da base, sublinhando que esse poder é ao mesmo tempo condição necessária à aplicação das políticas e um desafio a accountability e a responsiveness. 


\section{As políticas e os burocratas do nível da rua}

\subsection{A imprecisão dos objetivos das políticas públicas}

Desde a publicação do texto de Jeffrey Pressman e Aaron Wildavsky (1973) que o debate da implementação se tornou recorrente entre os analistas das políticas públicas e eles passaram a se preocupar com o que, da perspectiva do cidadão, de fato conta: os impactos das políticas para as pessoas e para os problemas a que elas são dirigidas. Mas ainda que essa atenção voltada aos determinantes e às consequências das políticas tenha iluminado a compreensão do processo político, ela ainda não foi suficiente para explicar como os programas aprovados são transformados em serviços no interior das agências, nem, principalmente, oferece explicação para os resultados deles: "(...) elas [as pesquisas] nos contam muito pouco sobre a implementação da política pública", porque "uma coisa é examinar os determinantes das decisões políticas e identificar seu impacto ou consequências, outra é prover a explicação para essas consequências" (Van Meter e Van Horn, 1975:447).

A discussão foi estimulada pelo reconhecimento de que os serviços prestados poderiam não ter qualquer impacto sobre o problema que eles supostamente resolveriam e, no decorrer dela, tornou-se cada vez mais evidente a necessidade de incorporar as contribuições produzidas pela teoria das organizações e, desde o texto seminal de Michael Lipsky (1980), pelos estudos das burocracias das ruas. A literatura passou a sublinhar a extensão em que os resultados da implementação são dependentes das burocracias, pois elas desempenham papel capital não só na execução das políticas que alocam os recursos públicos como também na própria tomada de decisão sobre quem ganha o quê do governo.

Os estudos da implementação interessam-se pela razão de as políticas ocorrerem, ou não ocorrerem, do modo como foi intencionado pelos autores, e eles apresentam evidências de que o desenho das políticas, os recursos devotados a sua execução e a validade de sua teoria causal modelam a aplicação das políticas públicas e seus resultados (Hill, 2003).

Outro fator decisivo na implementação é a organização, porque ela influi diretamente nos resultados dos programas governamentais, pois a dinâmica da interação entre ela e seus membros afeta o processo de trabalho e, por conta disso, influencia a quantidade e a qualidade dos serviços por ela prestados (Simon, 1997; March e Simon, 1993; Crozier, 1963; Crozier e Friedberg, 1977). A ação dos burocratas da linha de frente é mais uma variável na equação da aplicação das políticas, porque são eles que de fato traduzem os programas em bens e serviços concretos, quer dizer, os cidadãos são beneficiados ou punidos pelo poder público por meio dos funcionários que trabalham nos guichês; nos consultórios; nas salas de aula; nos pátios dos presídios; nas esquinas das ruas. Todavia, o agente da base tem de ir além da execução dos programas, porque muitas vezes os formuladores deles não sabem o que querem atingir com eles ou não sabem como alcançar os objetivos deles.

No debate público acerca da implementação não raro se encontra implícita a suposição de que os fins das políticas e os meios para sua execução estão bem definidos. Há muito tempo essa suposição foi posta em suspenso pelos pesquisadores e acumularam-se indícios 
de que frequentemente as políticas têm objetivos e significados vagos, dúbios e contraditórios e que isso ocorre algumas vezes porque os legisladores resolvem as controvérsias que surgem durante o processo decisório mediante uma linguagem de compromisso e de reticências. Quando a esfera legislativa não consegue solucionar os conflitos entre os objetivos das políticas ou apresentar esses fins de modo claro, ela transfere o problema para a área administrativa.

Os programas com propósitos vagos, gerais ou inconsistentes não são raros e "frequentemente, qualquer esforço para torná-los claros resulta na produção verbal sem significado ou na exposição de discordâncias profundas" (Wilson, 2000:26). Estas evidências sugerem que os executores das políticas têm de ir além da decisão de aplicá-las ou não e isso inclui o julgamento sobre o que elas significam e que resultados elas almejam. As regras e os procedimentos formais da organização não fornecem a referência para esse juízo, porque não podem estabelecer ou esclarecer os fins dos programas, então os aplicadores agem frequentemente de acordo com sua discricionariedade para fixar esses objetivos e, consequentemente, o modo mais adequado para atingi-los, ou seja, além de outros fatores examinados adiante, a vagueza dos fins na elaboração das políticas exige e amplia a ação discricionária dos executores imediatos.

\subsection{A margem de manobra dos burocratas da linha de frente}

As políticas são feitas pelas autoridades eleitas e pelos funcionários do topo e são executadas pelos atores do baixo escalão. Mas delegar a alguém atribuições é sempre arriscado porque, embora a designação seja feita a papéis, "de fato a delegação necessariamente envolve indivíduos concretos que têm interesses e objetivos que nem sempre coincidem com os do sistema formal" (Selznick, 1948:27). Por conta disso, os agentes podem apresentar resistências às diretrizes que acompanham a delegação e podem se desviar das normas e dos procedimentos formais no cotidiano.

O debate da burocracia é influenciado pelas reflexões de Max Weber, daí a relação hierárquica entre o topo e a base induzir ao entendimento de que os que se situam embaixo deveriam executar sine ira et studio as ordens emanadas de cima. Mas as pesquisas mostram que o tipo-ideal weberiano se desvia consideravelmente das burocracias do nível da rua, porque seus operadores desfrutam de ampla autonomia na decisão sobre quem serão os beneficiados e os punidos pelo governo, ou seja, eles não apenas executam as políticas públicas (policies), eles fazem também a política (politics).

Se as leis prescrevem os comportamentos que deverão ser punidos e se as legislaturas determinam a elegibilidade dos que serão afetados pelas políticas, no plano micro a aplicação das leis e a seleção dos que receberão os benefícios são dependentes da discrição dos burocratas de linha. Numa situação concreta, que conduta ameaça a ordem pública? O policial na rua é quem deve decidir. O número de pessoas que será atendido nos postos de saúde pode de- 
pender largamente das decisões dos funcionários. A administração do posto pode estabelecer a cota diária, mas não tem como assegurar a qualidade do atendimento na enfermaria ou no consultório. Os administradores sabem que a adoção de medidas que sofram sérias restrições dos trabalhadores da base pode provocar uma reação que atinja a qualidade do serviço e que ponha os gestores e os políticos sob a luz do público.

Não se pode esquecer de que os funcionários não necessitam violar as regras para não cumprir as ordens oriundas de cima. Ao contrário, basta que eles se apeguem a elas para justificar sua resistência. Se a norma obriga, ela protege também o agente na ponta do sistema. Como as condições reais de trabalho estão geralmente aquém não só das ideais como das necessárias, legitimamente os atores podem se recusar a trabalhar sob as condições existentes na agência ou, outro recurso à disposição, podem realizar as tarefas de acordo com a letra da lei. É a conhecida operação-padrão e que os franceses chamam de greve de zelo.

O texto de Michael Lipsky (1980) sobre a burocracia do nível da rua (street-level bureaucracy) tornou-se a referência no debate da importância das agências e dos agentes que concretizam o Estado perante o cidadão individual, no dia a dia. Mas a relevância dos atores do baixo escalão já havia sido indicada duas décadas antes. David Mechanic (1962) sublinhou que, nas organizações complexas, os participantes da base possuem amplo poder e influência que não estão associados às suas posições formais. Ele argumentou que as organizações podem ser muito dependentes de seus membros da linha de frente, porque eles podem obter, manter e controlar informações, pessoas e instrumentos que são importantes para o funcionamento delas e isso dá aos agentes poder informal, pois os superiores hierárquicos estão destituídos daqueles recursos e não podem regular o uso deles pelos subalternos, a não ser ao custo de reduzir a eficiência da organização, o que criaria problemas para eles próprios.

Todavia coube a Michael Lipsky realizar a primeira análise sistemática do que a partir de então ficaria conhecida como street-level bureaucracy:

Eu argumento que as decisões de burocratas do nível da rua, as rotinas que eles estabelecem e os artifícios que eles inventam para tratar com as incertezas e as pressões do trabalho efetivamente tornam-se as políticas públicas que eles executam. Eu sustento que a política pública não é mais bem compreendida como feita nas legislaturas ou nas suítes dos administradores do alto escalão no último piso. Estas arenas decisórias são relevantes, claro, mas elas não representam o quadro completo. À combinação dos lugares onde as políticas são constituídas, devem-se adicionar os escritórios lotados e os encontros diários dos trabalhadores do nível da rua (Lipsky, 1980:xiii; ênfase no original).

O Estado torna-se concreto para a maioria dos cidadãos por meio desses funcionários, porque das mãos deles saem os benefícios ou as punições que aqueles recebem do governo e que delimitam as vidas e as oportunidades deles. E, como ensinado pela teoria das organizações, não parece que se possa confiar nas normas e procedimentos formais como garantia de que os agentes públicos seguirão os objetivos declarados nas políticas e de que atenderão às exigências de accountability, de equidade e de responsiveness na aplicação dos programas. O 
fator fundamental para essa dúvida é a ampla discrição de que os atores da base usufruem na execução de seus misteres. ${ }^{1}$

Os burocratas do nível da rua carecem de tempo, de informação e de outros recursos necessários a uma apropriada tomada de decisão. Se a escassez desses recursos é crucial em qualquer processo decisório, ela o é ainda mais nas burocracias em que os atores têm de tomar decisões de pronto em situações imprevistas e/ou marcadas pela ambiguidade, no calor do momento, sob a pressão direta e imediata do público e eles têm de decidir o que fazer por si mesmos, sem a ajuda dos supervisores, dos guias de procedimentos ou de precedentes. Os imperativos da situação ajudam a explicar por que, apesar de os agentes terem pouca autoridade formal, eles dispõem de considerável discrição sobre as regras e os procedimentos que serão aplicados e sobre os bens e as sanções que serão distribuídos.

Apesar de o funcionário da esquina exercer seu ofício sob o constrangimento das normas e dos procedimentos, ambos proveem débil limitação e frágeis parâmetros para os julgamentos na linha de frente: "o trabalho ao nível da rua é, ironicamente, saturado de regras, mas não é obrigado por elas" (Maynard-Mood e Musheno, 2000:334). Há fatores que influenciam a discricionariedade: as tarefas a serem executadas; o contexto da tomada de decisão; as pressões da carga de trabalho; a cultura da organização; as regras e os constrangimentos; o ambiente externo da organização (Furlong, 1998; Balla, 2000).

O exercício da discrição é inevitável e necessário, porque as regras formais não podem dar conta de todos os casos concretos e, em geral, os recursos da agência estão aquém dos necessários para atender aos cidadãos, e, devido a isso, o poder discricionário do agente da base torna-se imprescindível para que a organização se amolde à realidade, funcione e atenda às pessoas. Mas reconhecer isso não implica negar os problemas que esse poder acarreta para o cidadão e para a democracia, porque, nesse regime, os eleitores escolhem as autoridades que deverão formular as políticas e listar os elegíveis. No entanto, os burocratas do baixo escalão comumente tornam-se os fazedores das políticas, sem que tenham de responder aos concidadãos do mesmo modo que as autoridades eleitas. A ampla margem de manobra deles põe a interrogação sobre seu controle.

\section{A monitoração dos agentes do baixo escalão}

\subsection{Os limites dos mecanismos de regulação}

Analisando as discussões acerca do poder discricionário dos burocratas, James Q. Wilson sublinhou que não existe um problema da burocracia e sim alguns e que a solução de cada um deles é, em algum grau, incompatível com as soluções de todos os outros:

\footnotetext{
${ }^{1}$ Para evitar mal-entendidos, deve-se sublinhar que os burocratas da linha de frente não desfrutam todos eles o mesmo grau de discricionariedade, pois ela depende do tipo de serviço prestado pela agência.
} 
Primeiro, existe o problema da accountability ou controle — fazer com que a burocracia sirva aos objetivos que têm a concordância nacional. Segundo é o problema da equidade — fazer com que a burocracia trate de modo igual os casos similares e sob a base de regras claras e conhecidas (...) Quarto é o problema da responsiveness - induzir os burocratas a irem ao encontro, com disposição e compaixão, dos casos que não podem ser postos numa regra singular e que parecem requerer, pelos padrões comuns de justiça e benevolência, que uma exceção seja feita (Wilson, 1967:4-5).

As dificuldades começam quando se percebe que esses valores nem sempre são compatíveis entre si. A equidade pode se chocar com a responsiveness, porque essa exige o tratamento diferenciado, que sejam levadas em conta as necessidades específicas de cada cidadão, enquanto aquela postula o tratamento igualitário. Do mesmo modo, a responsiveness pode se chocar com a accountability, pois se o burocrata deve agir de acordo com as necessidades de cada pessoa, ele talvez tenha de se afastar dos objetivos declarados do programa, porque esses fins formulados no alto não contemplam os casos particulares. Em resumo, em certas circunstâncias algum desses princípios terá que ser sacrificado em favor dos outros e a decisão sobre quando isso deve ocorrer fica à mercê sobretudo dos burocratas da linha de frente. Como lembrado por Michael Lipsky (1980), as burocracias do nível da rua incorporam o paradoxo de ter de realizar estritamente os objetivos que têm origem no processo político e, ao mesmo tempo, o trabalho requer improvisação e responsiveness.

Além do problema de eventuais choques entre os princípios que norteiam a prestação de serviços públicos numa democracia, o debate da monitoração dos burocratas da base tem de incorporar um elemento definidor de sua ocupação, que é o de enfrentar as reações diretas e imediatas das pessoas às suas decisões. Diferente das autoridades políticas e da alta administração, os atores na ponta do sistema não veem os cidadãos como abstrações, mas como indivíduos concretos, nos encontros face a face. Como sublinha a literatura, os políticos e os administradores do topo falam da abstrata delinquência juvenil, o policial tem de confrontar o adolescente armado; eles discorrem abstratamente sobre a dificuldade de aprendizado, o professor tem à sua frente o aluno que não consegue acompanhar o curso (Lipsky, 1980; Maynard-Mood e Musheno, 2000).

Esta situação faz com que os agentes da base enxerguem por vezes seus superiores como elaboradores de programas que são distanciados da realidade e impraticáveis e, por conta disso, os burocratas de linha passam a duvidar de que as autoridades estejam realmente preocupadas em solucionar os problemas da sociedade. Essa percepção é uma variável que impõe obstáculos à regulação desses agentes, porque ela abala a legitimidade da hierarquia. Não há por que supor que esses trabalhadores duvidem todo o tempo da legitimidade dos gestores, contudo, à medida que, aos olhos deles, as diretrizes da hierarquia afastam-se das condições reais de trabalho, ameaçam seus interesses privados ou ignoram as características dos cidadãos individuais, eles tendem a desobedecê-las parcial ou totalmente. Como eles não são vigiados de perto pelos supervisores, eles têm a oportunidade de executar suas tarefas de acordo com suas preferências e com suas concepções do público a que servem. 
Devido ao poder discricionário dos burocratas, desde a década de 1950 acentuou-se a preocupação com a fiscalização deles. Grosso modo, podem-se apresentar duas perspectivas que orientam a discussão: a top-down vê os formuladores das políticas como os atores principais e concentra sua atenção sobre os fatores que podem ser manipulados ao nível do topo. A bottom-up enfatiza os grupos-alvo e os prestadores de serviço, argumentando que as políticas são feitas também na base (Matland, 1995; De Leon, 1999).

A teoria da agência é muito influente entre os pesquisadores que concentram sua atenção no alto escalão. De acordo com ela, o comprador de bens ou de serviço é o principal; o vendedor, o agente (principal-agent model). A aplicação dela tem alguns pressupostos básicos: a relação entre os líderes eleitos e os burocratas é hierárquica; os burocratas estão limitados pelo contrato a servir às autoridades políticas e sua responsabilidade primária é implementar a lei. Trata-se de uma relação gerida pelo contrato especificando o que o agente deve fazer e o que o principal tem o direito de receber. O chefe do Executivo e os parlamentares, por exemplo, são os compradores/consumidores, e os burocratas, os vendedores/fornecedores. Assume-se que, com o tempo, os interesses de ambos divergem entre si, mas a situação é mais favorável aos agentes, porque eles têm mais informações que seus principals, logo estes devem monitorar aqueles de modo a assegurar o controle político sobre eles.

Orientados por esta teoria, pesquisadores concluíram que, sendo o controle um assunto econômico envolvendo a manipulação de incentivos ao nível micro, é possível a regulação política das burocracias, isto é, há como fazer o burocrata responder à autoridade política (Wood e Waterman, 1991; Waterman et al., 1998). No entanto, os resultados dessas pesquisas têm alcance limitado: o baixo número de casos estudados e a pouca variedade de agências pesquisadas não autorizam a generalização (Wood e Waterman, 1991; Waterman et al., 1998; Wilson, 2000; Balla, 2000). Além disso, há problemas com seus pressupostos analíticos.

A preocupação principal são os mecanismos que possam reduzir a probabilidade de os agentes deixarem de fazer as tarefas que lhes são designadas. O mecanismo preferido é o do incentivo econômico, que é vinculado ao desempenho da agência e/ou do ator. De fato, a medida dos resultados da organização e dos trabalhadores pode ser um fio condutor para regular os últimos; entretanto, como salientam Simon (1991) e Weisbrod (1989), os sistemas de recompensa são efetivos quando podem medir acuradamente as contribuições individuais e a produção da organização. Se os índices para avaliarem os resultados forem inapropriados, seja porque eles não têm como identificar os acréscimos individuais para o produto final seja porque não medem as variáveis corretas, então o sistema de recompensas pode ser ineficiente ou até mesmo contraproducente.

As pesquisas empregando a teoria da agência dirigiram-se a organizações onde, em princípio, os resultados poderiam ser mensurados; entretanto, há agências em que a medida do resultado não é possível ou onde, como no caso do policiamento ostensivo, o processo é mais relevante do que o produto: o modo como o policial restaurou a ordem pública pode ser mais importante do que a ordem restaurada. O processo só poderia ser avaliado se o fiscal estivesse presente no momento da ação, mas, nesse caso, o problema da regulação não estaria 
posto, porque o executor estaria sob a supervisão imediata e, como regra, o debate do controle refere-se às situações em que a vigilância não é imediata.

Além disso, a falta de clareza dos objetivos contribui para os obstáculos impostos à avaliação da performance. A ausência dessa nitidez não é rara na formulação das políticas, como discutido na primeira seção. Quando os fins da organização e das políticas são imprecisos, o desempenho como um todo e o do agente não são fáceis de serem aferidos. A polícia e a escola têm objetivos vagos: assegurar a ordem pública e educar as crianças. Os valores conflitantes numa sociedade muito heterogênea fazem com que haja discordâncias entre os cidadãos acerca da definição de ordem pública e de educação.

Torna-se difícil monitorar os atores a partir de seu desempenho quando os critérios de sucesso são obscuros. Até se podem conhecer os inputs e os outputs do sistema, mas pode-se saber muito pouco sobre o processo de transformação de um em outro, além do que há efeitos que só podem se manifestar muito depois de o processo ter sido concluído (Bouchard e Carrol, 2002; Friedberg, 1993). A aferição inadequada do desempenho reduz o poder regulador dos resultados, porque os atores podem considerá-los inválidos ou injustos e desprezá-los. O recurso para se evitarem as dificuldades da teoria da agência, o conhecido todas as outras coisas sendo iguais, pode não ser de grande valia porque, como lembra James Q. Wilson, raramente todas as outras coisas permanecem iguais. E ele completa:

(...) sob as condições de vagueza e de objetivos conflitantes não é surpreendente que os economistas não tenham feito muito progresso em encontrar até mesmo solução teórica para o problema do shirking. Surpreendente é que os burocratas trabalhem como um todo, apesar de todas as oportunidades que eles têm para não fazerem as tarefas que lhes são assinaladas (Wilson, 2000:156).

Não se deve esquecer de que os incentivos encontram seus limites em outros fatores que também influenciam a discrição: a expectativa dos pares e as normas profissionais (Wilson, 2000; Evans, 2011). A expectativa dos pares é mais relevante para se compreender o comportamento dos agentes do que suas atitudes. Os incentivos podem concorrer com as atitudes e vencê-las, mas tendem a perder quando se confrontam com as expectativas dos parceiros, isto é, há maior probabilidade de os atores preocuparem-se mais com a reação dos colegas ao seu comportamento do que com prêmios ou punições. As normas profissionais são outra importante variável que influencia a discrição. Elas e a expectativa dos pares contribuem para monitorar os agentes, mas reduzem o poder da organização sobre eles.

Estas ressalvas dirigidas à regulação dos burocratas seguindo-se a teoria da agência não são para negar que é possível controlar via medição dos resultados e recorrendo-se aos incentivos seletivos, mas sim para sublinhar seus limites, sobretudo se se quiser aplicá-la às burocracias em que o processo de execução das tarefas pode ser mais importante que os produtos ou cujo resultado final não pode ser atribuído exclusivamente a elas e a seus atores.

Se essas observações sobre a fiscalização na ponta do sistema podem ser válidas para as burocracias públicas e privadas, há um fator importante que acentua os obstáculos quando se trata das primeiras: o caráter involuntário de seus clientes (Lipsky, 1980; Downs, 1967). 
As empresas privadas podem receber aviso do mercado quando seus consumidores não estão satisfeitos, porque simplesmente eles desaparecem. Não é o caso da burocracia pública, porque ou ela monopoliza os serviços, ou a opção para os clientes é muito custosa, ou eles não podem optar se querem ou não ser atendidos pelo Estado. No caso do sistema criminal a obviedade do caráter involuntário salta aos olhos, mas isso é verdadeiro também para outras situações: o cidadão que quiser habilitação para dirigir tem de ir às agências públicas, não importa se elas são eficientes ou não; os pais de baixa renda só podem matricular os filhos nas escolas do governo, independente da qualidade delas; os cidadãos pobres não podem dispensar os postos de saúde governamentais nem os vários serviços sociais, sofram humilhações ou não. Independentemente de como o cidadão seja tratado, as burocracias públicas não perderão o cliente; logo, a ausência dele não servirá como alerta aos administradores.

\subsection{Os supervisores da ponta do sistema}

Dessas reflexões não deriva a conclusão de que a agência, através de seus gerentes e administradores, não tenha poderes para persuadir e induzir os trabalhadores a caminharem em direção aos objetivos dela, ou seja, de que ela não disponha de recursos para limitar o poder discricionário dos agentes na aplicação das políticas. A organização importa quando o tema é a regulação da conduta de seus membros. Se for verdade que os funcionários do baixo escalão têm ampla margem de manobra, eles não atuam, contudo, num vácuo institucional. A organização produz constrangimentos que modelam a discrição deles: se as regras formais não são a determinante primária do comportamento dos burocratas das ruas, elas não são também sem efeitos, porque eles não as podem ignorar em suas escolhas do curso de ação a ser adotado, vez que a violação a elas implica punição. As sanções previstas, as formas de aplicá-las e o poder real de quem deve aplicá-las são variáveis relevantes na equação do controle.

Desde a década de 1980, pesquisas têm examinado os modos de regulação dos burocratas da base e seu sucesso em influenciar seus comportamentos, mas os saldos acumulados trazem pouca compreensão da importância das influências políticas e gerenciais na conduta dos atores (May e Winter, 2007). Apesar dessas dificuldades, as agências públicas funcionam e prestam serviços variados aos cidadãos; portanto, os gerentes, sobretudo os que trabalham na ponta do sistema, conseguem assegurar a integração necessária à ação organizada.

Há estudos dos burocratas do topo e da base, mas deixam-se de lado os atores que têm a função imediata de traduzir as regras, os procedimentos e de esclarecer os objetivos da agência para os executores finais: os supervisores da linha de frente. Eles têm mais oportunidades de acompanhar o processo de execução e, portanto, têm mais chances de identificar os erros e de intervir antes de os resultados indesejados ocorrerem. Para tornar o controle efetivo, eles têm à sua disposição prêmios e punições para distribuírem: promoção, local de trabalho, tipo de tarefa, tornar o trabalho mais ou menos desejável. Como outros sublinharam, os supervisores da ponta do sistema são operadores importantes para a agência, ainda assim não se tem examinado o papel deles de modo cuidadoso (May e Wood, 2003; Pandey e Wrigth, 2006; Brewer, 2005). 
A relação entre os burocratas da base e os gerentes é inerentemente conflituosa, porque ela é uma relação de dependência mútua. Os gerentes precisam que os trabalhadores executem bem as tarefas, e esses querem evitar as punições e desejam receber as recompensas administradas por aqueles. Porém, se se trata de relação de reciprocidade, ela é desigual. Se o desempenho dos supervisores depende de os subalternos se disporem a executar as tarefas acima da eficiência mínima, a performance dos últimos não é muito dependente dos primeiros e, se os subordinados não estiverem interessados nos prêmios, eles não necessitam ir além do mínimo obrigatório no exercício de suas funções, o que pode acarretar danos aos cidadãos que precisam dos serviços e que ficam à mercê de os funcionários irem além de suas obrigações mínimas. No caso de insatisfação do público, o alvo da crítica serão os administradores e os gerentes, que serão cobrados pela ineficiência da organização. Como regra, os atores da base não têm de se preocupar com sua imagem pública, ao contrário dos políticos, dos administradores e dos supervisores intermediários, e esta situação aumenta os recursos de poder dos servidores do nível da rua.

No cenário de conflitos e compromissos que marcam as interações no interior das organizações, os burocratas exercem sua tarefa de prestar serviços ao cidadão, principalmente ao de baixa renda, assegurando-lhe educação, saúde, segurança, renda. Essas tarefas são concretizadas, muitas vezes, graças ao poder discricionário dos agentes da base. Porém, a mesma discricionariedade que favorece os indivíduos paira como uma ameaça sobre eles.

No próximo tópico, para ilustrar alguns argumentos aqui apresentados, analisar-se-á uma burocracia do nível da rua: a organização policial. A polícia está associada à produção de segurança nas democracias, mas, paradoxalmente, ao mesmo tempo que é uma garantia do exercício da liberdade, ela é uma potente, e sempre presente, ameaça a essa liberdade, ou seja, ela é produtora também de insegurança para o cidadão. A organização policial e o poder discricionário de seus agentes merecem mais atenção analítica.

\section{Os burocratas das esquinas ${ }^{2}$}

A administração da aplicação da lei é um tipo crítico de administração pública. Porém, ainda que o aparelho policial seja sempre citado no debate da burocracia das ruas, "existe uma escassez de literatura dirigida especificamente às organizações policiais, seja no domínio da administração pública seja em pesquisas relacionadas, especialmente na ciência política" (Nicholson-Crotty e O’Toole Jr. 2004:4). No Brasil, a segurança pública tornou-se tema político relevante nos anos de 1990 e moeda de troca nas eleições. Ainda assim, a instituição policial não se tornou objeto de análise mais sistemática sob a ótica da organização e da burocracia.

\footnotetext{
${ }^{2}$ Todos os dados empíricos da PMBA são oriundos de nossa tese de doutorado. As falas selecionadas para ilustrar este artigo foram obtidas através de entrevistas semiestruturadas e em profundidade, com 41 oficiais policiais militares de todos os postos (Oliveira, 2005). Deve ser lembrado de que essa polícia é responsável pelo policiamento ostensivo, portanto as análises que seguem não podem ser transpostas automaticamente para o policiamento investigativo.
} 
A polícia é uma típica burocracia do nível da rua, talvez a mais típica, pois seus agentes trabalham literalmente nas ruas, 24 horas por dia, longe do olhar dos supervisores e seu trabalho é primordialmente o processamento de pessoas.

Apesar de no país existirem trabalhos empíricos bem qualificados sobre a força pública, na academia brasileira o debate em torno dela é mais normativo do que empírico, ou seja, discorre-se mais sobre o que a polícia deveria ser em vez de tentar compreender as existentes no Brasil - as características organizacionais da agência, o que seus agentes fazem no cotidiano, como eles fazem isso e por que eles fazem isso do modo que fazem - , comparando-as com as de outras democracias. Analisar a polícia como burocracia pode ajudar a entenderem-se mais e melhor suas tarefas concretas, seus recursos reais, seus conflitos internos e os interesses privados de seus membros e, por conseguinte, pode ser mais útil para discutirem-se as questões normativas como a de seu controle.

\subsection{A organização policial e seu mandato}

As burocracias frequentemente favorecem alguns cidadãos em face de outros e tratam algumas pessoas baseadas em estereótipos, ainda que o tratamento igualitário seja a política oficial. Michael Lipsky argumentou que, para entender como e por que as organizações atuam algumas vezes de modo contrário às suas regras e a seus objetivos, se necessita saber como as normas são vivenciadas pelos trabalhadores na agência, que latitude eles desfrutam para agir conforme suas preferências e que outras pressões no trabalho eles experimentam (Lipsky, 1980). Assim, a compreensão da atividade policial demanda melhor conhecimento da organização policial e da situação de trabalho de seus agentes.

Essa agência ocupa a ponta do sistema penal, ela lida direta e imediatamente com as ocorrências que violam, ou parecem violar, a ordem legal. Essa posição favorece a desavença com as outras instâncias do sistema criminal, como o Ministério Público e o Judiciário, que entram em ação quando a fase aguda do conflito foi ultrapassada, as evidências foram colhidas, o público já foi disperso. Para tomarem suas decisões, os promotores e juízes dispõem de tempo para analisar as evidências, consultar os colegas, os manuais e os precedentes e não experimentam as ameaças e ofensas dos envolvidos na contenda, quando menos não as vivenciam na mesma extensão e intensidade que os policiais.

Essas diferenças produzem uma tensão permanente entre a polícia e as instâncias da cadeia penal que têm como tarefa revisar as decisões tomadas pelos patrulheiros nas esquinas, porque esses julgam que as decisões delas, sobretudo do Judiciário, são morosas e indiferentes à realidade das ruas e, por conta disso e por vezes, a legitimidade dessas esferas, enquanto reguladoras da atividade policial, é posta em dúvida pelos guardas. Devido a isso, não é muito provável que as revisões judiciais e da promotoria induzam a conduta dos policiais nas ruas, e esta reação deles - ignorar o porquê de suas ações terem sido revistas — está apoiada na posição que eles ocupam no sistema penal: se o Ministério Público e o Judiciário são funcionalmente dependentes da eficiência da polícia, essa, em seu trabalho cotidiano, não é tão 
dependente daqueles, o que lhe confere, na prática, ampla autonomia diante das instâncias que lhe são superiores e que têm o poder formal de limitar sua discrição.

Outras observações sobre a agência policial são necessárias para que se possa melhor compreender sua relação com o público. Ela age na fronteira do Estado com a sociedade e, para efetivar essa mediação, ela pode recorrer à violência e a outros meios de ação não negociáveis, isto é, meios que não dependem do consentimento dos cidadãos. O recurso a esses instrumentos gera tensão duradoura na interação entre a agência e o coletivo social. Os conflitos entre o público e os burocratas da base são crônicos, porque aquele alimenta expectativas que esses não podem atender (Lipsky, 1980). Na burocracia policial esse conflito é agravado pelos meios a que seus agentes podem recorrer em seus contatos com os cidadãos. A polícia é um aparelho que "suscita reações e julgamentos contrastados, fortemente influenciados por reações afetivas mais ou menos conscientes e por preconceitos ideológicos" (Loubet del Bayle, 1981:541).

A natureza da atividade policial por si só causa constrangimento a uma sociedade que se apresenta como pacificada. Para eliminar a violência privada como meio tolerável de resolução de conflitos que emergem do convívio social, a sociedade moderna criou uma corporação cuja especialidade é o gerenciamento da força coerciva que ela mesma abomina e isto faz com que ela apresente seu instrumento de violência de forma que ele seja assimilável por seu ideal de pacificação, a exemplo de afirmar que o papel do policial é proteger o cidadão. As pessoas parecem esquecer que a proteção de alguém implica, algumas vezes, a necessidade de agredir fisicamente, até mesmo matar, outro cidadão: "nada mais enganoso que a distinção entre a boa polícia que protege oposta à má polícia que reprime" (Monjardet, 1996:9), pois é a mesma agência que pratica as duas ações no mesmo movimento, contudo "para reconciliar a si própria com sua polícia, a sociedade moderna a envolve em ocultação e circunlóquios que promovem a aparência de que a polícia é alguma outra coisa além do que ela realmente é [um instrumento de distribuição de força não negociável]" (Klockars, 1991a:541).

Se a imprecisão das leis a serem aplicadas, a natureza da atividade policial e os recursos que se podem empregar na resolução de conflitos são por si mesmos geradores de problemas na interação da polícia com o público, a fluidez do mandato policial - manter a ordem pública - agrava essa situação.

Os especialistas enfatizam tanto a dificuldade para se definir a função da polícia — "Público e polícia sofrem da ausência de uma clara, não ambígua e universal concordância na declaração do mandato policial em nossa sociedade" (Skolnick e Fyfe, 1993:242) — como o poder discricionário de seus agentes - police discretion — , que seria o determinante primário do policiamento onde ele realmente conta, isto é, nas ruas (Bittner, 2003; Reiss, 1971; Muir, 1977). Eles sublinham que o policiamento não é uma prática que possa ser bem compreendida a partir dos códigos formais que prescrevem a atuação do agente, porque a conduta desse é primariamente condicionada por sua interação com o público. Anthony Downs (1967) argumentou que, quando o meio ambiente é muito incerto e cambiável, as organizações tendem a agir mais sob os procedimentos e as estruturas informais. A incerteza e a mutabilidade são a realidade das ruas, onde os policiais executam seus ofícios. 
Pode-se argumentar que nenhuma ocupação é bem compreendida a partir das normas formais para ela prescritas, mas não se deve esquecer de que o trabalho policial é marcado pela imprevisibilidade dos eventos, pela falta de conteúdo prévio das tarefas a serem realizadas nas ruas e pela invisibilidade dos encontros entre o agente e as pessoas. Esse conjunto não caracteriza outras atividades, por conta disso o policiamento é mais difícil de ser compreendido a partir das regras institucionais do que outras ocupações. Como sublinhado por outros autores, isso se deve, sobretudo, à fluidez do mandato da agência — preservar a ordem pública - , o que faz com que ela lide com uma variedade de temas que nenhuma teoria pode servir de guia para estabelecer previamente o modo de execução do ofício (Monjardet, 1996; Manning, 1997).

Essa característica do policiamento — o conteúdo maleável — não permite à hierarquia prescrever o modo como os agentes devem executar as tarefas com que eles se confrontam nas ruas, ela apenas pode emitir formulações genéricas sobre a realização do ofício na via pública, portanto haverá obstáculos à avaliação dos agentes a partir de seu desempenho nos afazeres. Logo, pode-se presumir que a polícia é uma burocracia do nível da rua com sérias dificuldades para monitorar seus atores.

No debate da regulação da força pública deve ser lembrado de que ela apresenta uma característica rara entre as organizações: produzir os próprios agentes. A regra é o profissional ser gerado por uma organização distinta da que ele vai atuar. Mas, na polícia, o processo de socialização do profissional ocorre integralmente dentro da agência. Outro dado relevante é o de a administração ser constituída exclusivamente pela profissão, o que torna impossível aos executores imediatos alegarem ingerência indevida dos leigos quando os supervisores intervierem em suas práticas de trabalho. Em contrapartida, como os gestores experimentam a condição policial, eles podem tender a desqualificar as críticas dirigidas aos seus subordinados pelos que não conhecem a realidade do policiamento, ou seja, os agentes da ponta do sistema podem contar com a cumplicidade corporativa da direção. Esse estado de coisas gera um vínculo especial entre os profissionais e a organização: a profissão só existe dentro dela (fora dela, pode-se ser agente de segurança privada, mas não policial) e sua administração está exclusivamente nas mãos da profissão. Essa característica organizacional é uma importante variável na resistência dos atores às ações de reformas vindas do exterior e às de revisão externa de sua conduta.

Apesar das dificuldades para se regular o aparelho policial e que derivam de suas características organizacionais, seu controle é essencial, porque seus agentes estão autorizados a usar o constrangimento físico e eles interferem direta e imediatamente nas liberdades civis. Há o argumento de que a natureza do trabalho na linha de frente é especialmente problemática, porque as decisões e as ações ao nível da rua são guiadas menos por regras formais e treinamentos e mais por crenças e normas informais, que são mais resistentes às mudanças (Maynard-Mood e Musheno, 2000). Os trabalhos empíricos sobre a polícia oferecem indícios que confirmam essa asserção. No entanto, nem os estudos da burocracia, em geral, nem os da força pública, em particular, descartam a possibilidade de regulação dos agentes do baixo escalão. 
O debate do controle dos funcionários que tratam diretamente com os cidadãos tem que incorporar a concepção que aqueles elaboram de sua interação com estes, ela é relevante para se compreenderem as ações na linha de frente (Lipsky, 1980), inclusive as ações dos supervisores imediatos, dos que têm a incumbência de fiscalizar os executores na ponta. No caso da Polícia Militar da Bahia eles são o major, o capitão e o tenente.

\subsection{A interação público-policial: a visão dos gerentes da ponta do sistema}

Em Salvador, o policiamento ostensivo foi descentralizado durante a década de 1990 e passou a ser responsabilidade das companhias. A cidade é dividida em várias áreas e em cada uma delas é instalada uma companhia. O major, o capitão e o tenente trabalham nelas e são incumbidos da supervisão das praças — os sargentos e os soldados —, isto é, dos atores que policiam as esquinas da cidade.

As falas dos oficiais que servem para ilustrar alguns argumentos apresentados tratam de sua percepção do público, dos mecanismos de controle e seus empecilhos. Sobre o tipo de policiamento a que o público aspira, os oficiais declararam:

Eu posso dizer esta experiência na prática, porque já comandei uma companhia, e, neste município, nós tínhamos três ou quatro tipos de clientela: a população carente, sofrida com a ação dos marginais; tinha a população de elite, que não queria a polícia por perto; a do comércio, que queria a polícia perto. Cada clientela desta queria um determinado tipo de policial. Eu já participei de reuniões com segmentos da comunidade de determinados bairros que eles pediam pra que nós eliminássemos os marginais: "não, a única coisa que se quer aqui é que vocês matem aqueles que são marginais, mais nada". Outros não querem ver a polícia na porta, os condomínios de luxo. Outros querem ver o policiamento lá direto, inclusive oferecendo até benefícios. Então, é difícil, porque é uma sociedade muito complexa, muito diversificada, principalmente onde eu atuei como comandante (Cap. I).

Primeiro que a própria população não sabe o que quer. Quer dizer, nós sabemos talvez a polícia que não queremos, mas a polícia que queremos, nós não sabemos. Nós queremos uma polícia para os outros. Então, eu sou permissivo, eu sou até omisso com relação a uma ação mais violenta da polícia se não for contra mim ou contra algumas pessoas ligadas a mim ou a meu grupo social (...) a partir do momento que esta ação de qualquer forma se dirige contra mim, aí, a polícia já não presta, "não é bem assim, não pode agir desta forma" (Maj. B).

Nos discursos são relatadas as demandas heterogêneas e contraditórias dirigidas pelo público à agência do governo. A complexidade da sociedade com seus inúmeros grupos defendendo interesses que se chocam entre si e a variação das preferências dos indivíduos de acordo com os contextos emergem nessas falas. Segundo os informantes, a depender do interesse circunstancial de cada fração do público, demandam-se aos policiais práticas que não respeitam o direito. 
Não se trata de particularidade local, fruto do autoritarismo da sociedade brasileira, ou da experiência recente com a democracia, ou do caráter militar da agência em questão. As falas desses atores são similares às de seus pares nos EUA, Inglaterra e França. As semelhanças não são surpreendentes, porque todas essas corporações lidam com coletivos sociais que têm variados grupos de interesses e que são atingidos diferentemente pelos problemas da segurança pública e que, por conta disso, têm concepções distintas acerca da tarefa da agência policial. Entretanto, o mais importante são as prováveis consequências dessas solicitações contraditórias, pois, quanto mais heterogêneos são os sentimentos da coletividade, mais os objetivos da burocracia conflitam entre si (Lipsky, 1980) e, por conseguinte, mais liberdade de ação é dada aos trabalhadores na ponta do sistema, o que lhes permite atuar de acordo com suas preferências.

Além disso, as demandas contraditórias podem servir de argumento aos supervisores para justificarem suas dificuldades na monitoração de seus subordinados, porque esses ficariam numa situação difícil diante das pressões diretas das pessoas envolvidas no conflito. Ainda que os gerentes declarem que os funcionários devem se comportar de acordo com as regras formais, eles podem acreditar que a situação enfrentada nas ruas não permite interpretação simples sobre a conduta concreta do ator.

Como analisado anteriormente, uma característica fundamental do burocrata da rua é ter de tratar com as reações diretas e imediatas das pessoas e, muitas vezes, ter de responder a elas de pronto, o que não lhe permite avaliar detidamente as circunstâncias. No caso da polícia, essa situação é agravada pelo fato de os agentes lidarem com eventos que envolvem sua integridade física e a de terceiros. A morosidade da decisão — isso pode significar apenas alguns minutos - pode acarretar consequências irreversíveis para o público e para eles próprios. Esse problema inerente ao policiamento é potencializado pelas solicitações de práticas contraditórias, porque, como afirmam alguns autores, esses pedidos aumentam a ambiguidade do papel do agente e, portanto, obscurecem o tipo de comportamento apropriado e funcional para executar as tarefas e isso causa considerável dubiedade para os gerentes médios (Pandey e Wrigth, 2006).

Se a percepção dos supervisores de linha for relevante para sua ação concreta, a concepção que eles apresentaram indica problemas na fiscalização dos subalternos: como, para eles, as pessoas não sabem o que querem, as queixas contra a conduta indevida podem vir a ser por eles desqualificadas, vez que eles podem interpretar os atos irregulares dos atores como parcialmente resultantes das preferências conflitantes dos grupos e dos indivíduos atendidos. Além disso, se as reclamações contra uma ação policial forem formuladas por quem não é atingido comumente pelos problemas que geraram a ação, elas correm o risco de ser avaliadas pelos supervisores como queixas de parcela do público que não vivencia os dramas de outras frações sociais. Nestas situações, o resultado da revisão interna de conduta talvez não venha a ser o esperado pela sociedade.

Para analisar melhor a tensão entre a polícia e o público, deve-se insistir na imagem que os oficiais constroem da sociedade, mais especificamente, como eles concebem e avaliam a imagem pública da profissão: 
Na hora que você coloca a farda e vai pra rua, você sabe que já tá sendo bem-visto por alguém e recriminado por outra pessoa, e, aí, é complicado. Chega o ponto que você entra no estabelecimento comercial, porque você tá com fome e você quer comprar comida, e as pessoas ficam lhe olhando com desconfiança. Eu faço questão, por exemplo, quando eu tô fardado e entro num restaurante, coisa parecida, eu faço questão de sair com a nota fiscal na mão, bem visível, porque é muito difícil, você se sente rejeitado, diminuído. Se você não tiver boa educação doméstica, uma base doméstica, uma autoconfiança desenvolvida, uma boa estrutura, você vai se sentir escória, resquício, resto da sociedade (Cap. A).

Tem gente que quer desfazer de você, porque você é policial. A primeira coisa que a pessoa diz é: "policial não estudou"; "não estudou, ora, vai ser policial", mas isto hoje é diferente. Você tá vendo a concorrência no vestibular pra se entrar na Academia (Ten. I).

Não é fácil, companheiro, passar uma noite de 12 horas trocando tiros, correndo atrás pra dar segurança a uma população que não reconhece. O cara toma na cara e continua fazendo todo dia, mas se ele não é reconhecido por fora, mas ele é reconhecido aqui dentro. Nós temos que valorizar nosso soldado, porque, por incrível que pareça, quem trabalha na parte operacional ganha menos, é visto como resto pela Instituição. Eu posso falar porque já senti na pele, tá ali pra combater: combateu certo, bem; combateu errado, pau (Maj. C).

De acordo com os discursos, o policial é um profissional distinguido de modo negativo pela sociedade. Mas convém sublinhar a fala do capitão A quando ele aborda a desconfiança do público em relação ao patrulheiro: ele faz questão de exibir que o produto foi adquirido de modo legal e não fruto da corrupção. Se o trabalho do policial assenta-se na suspeição generalizada (Klockars, 1991b), há o reverso da medalha: o fato de ele situar-se nas fronteiras da sociedade e lidar com o mundo do crime faz com que ele seja percebido como suspeito pelo cidadão. Não é adequado associar essa desconfiança ao histórico de corrupção e de uso excessivo de força de dada corporação, porque a percepção de que os indivíduos desconfiam do guarda e da ingratidão do público é alimentada por este profissional independente da agência em que ele trabalha (Monjardet, 1996; Manning, 1997).

É difícil supor que essa concepção dos agentes não tenha impacto em sua avaliação das denúncias que venham da sociedade: se, independentemente de como o policial se comporte, os cidadãos depreciam-no, querem desfazer dele — segundo os oficiais —, por que então o supervisor não suspeitaria de que numa interação concreta entre o agente e seus concidadãos aquele não foi tratado com animosidade por esses e isso teria provocado a reação do guarda de que o indivíduo agora se queixa?

Os grupos sociais não costumam tratar com seriedade as reclamações contra algum de seus membros, se eles acharem que o reclamante não mostra a deferência que para eles seu coletivo merece: nas delegacias comuns, as queixas das mulheres agredidas eram recebidas com desprezo pelos policiais do sexo masculino, porque esses achavam que provavelmente elas não trataram os homens com o respeito que lhes era devido e que, portanto, elas não foram agredidas, elas foram punidas; o mesmo se aplica às denúncias de vítimas homossexuais 
contra agressores heterossexuais. Apesar de esse comportamento - desqualificar o queixoso - ser comum, sobretudo nos grupos profissionais, convém lembrar que o policial está autorizado a usar a força e isto torna a desqualificação do público mais grave que em outras ocupações, por conta da natureza dos danos que podem ser provocados por esse burocrata do nível da rua, o que torna mais séria a questão do controle do policial.

A PMBA tem um mecanismo de revisão interna da conduta: as corregedorias. Todavia, esse modo de regulação interno é afastado da rua e, embora necessário, é acionado depois do estrago causado. Portanto, importam mais os mecanismos de inspeção adotados pelos supervisores na ponta do sistema. Os oficiais policiais militares reconhecem e aceitam a police discretion. Porém sabe-se que esse poder provoca abusos. Como ele não pode ser extirpado, porque está inscrito na própria atividade, resta saber o que os oficiais sugerem como forma de evitar ou reduzir os excessos que a margem de liberdade pode gerar:

Muitas vezes o policial faz como o médico, ele toma a solução ali mesmo, lhe dá o remédio ali mesmo, o remédio que ele acha que é mais apropriado. Por isto, este policial de ponta, este policial de rua tem de ser devidamente preparado, ele tem de ser devidamente instruído e ele tem que ter uma capacidade de entendimento do que tá fazendo muito grande pra que ele consiga dar encaminhamento de forma mais correta... Cabe ao policial ter consciência do que vai fazer, e fazer com que este problema seja passado pra frente às vezes é muito mais difícil do que solucionar ali. Por isto que muitas vezes ele soluciona pelo lado do bem, com aconselhamento, com apartar de uma briga, com, sei lá, uma instrução, uma notificação, e, muitas vezes, ele soluciona com a porrada, com a agressão, com o xingamento, com outras atitudes que não são as mais corretas (Cap. D).

A dificuldade é grande no nível de quem está no comando, a responsabilidade maior de passar esta missão, de passar aquilo que está dentro de seu pensamento, ou o que ele imagina que é a melhor forma de fazer policiamento, de resolver as questões externas, questões lá no momento onde elas estão acontecendo. Por isto que eu disse anteriormente sobre o policial pra trabalhar no PO deve ser um homem bem qualificado, bem formado (Maj. B).

Todas as organizações operam dentro de zonas de incerteza, e as ruas constituem a principal zona de incerteza da corporação policial, pois a hierarquia pode fazer muito pouco em relação ao controle imediato dos patrulheiros. Controlar os agentes em espaços confinados é diferente de regulá-los nas esquinas da cidade. Parece ser devido, sobretudo, à natureza da atividade de policiamento que os oficiais apostam na qualificação profissional como meio adequado para regular a conduta dos agentes. De fato, a profissionalização pode contribuir para o controle, mas as coisas são mais complexas, como indicado neste artigo. Não há espaço para argumentar melhor, mas é suficiente lembrar que a profissão compete, com vantagem, com a organização em termos de influenciar a conduta do agente e, embora as associações profissionais declarem o contrário, esta influência não se dá prioritariamente em benefício dos clientes nem é favorável à intervenção do leigo (o público) nos afazeres do experto, e os interesses da profissão podem estimular os agentes a desviarem-se dos fins organizacionais. 
A formação profissional não parece ser suficiente para os supervisores também. Isso foi evidenciado quando eles foram interrogados sobre o mecanismo que concebiam como mais eficiente para assegurar a boa conduta dos policiais nas ruas e eles responderam que seria a consciência dos agentes, porque é muito difícil acompanhar o homem a pé. Ao fim e ao cabo, apela-se à consciência de um ator que atua isolado e não pode ser acompanhado de perto pelo fiscal, e que se defronta com situações que os regulamentos não dão conta. Como os supervisores são policiais, eles sabem que não podem jogar todas as suas fichas nas regras formais como meio de garantir o bom comportamento do funcionário nas esquinas; por isso há o recurso à sua consciência.

Evidente, podem-se recorrer também aos incentivos seletivos, mas os limites desses como modo de regulação de conduta são evidenciados no trabalho dos patrulheiros. Como assinala James Wilson, a polícia é uma coping organization, isto é, um tipo de agência em que não se podem observar nem o que seu operador-chave está fazendo nem os resultados (outcomes) da ação. Além disso, ela se orienta por um objetivo não operacional — a ordem pública -, quer dizer, por um fim que visa um estado desejado futuro que não pode ser comparado sem ambiguidades a um estado real ou presente; por causa disso, também as medidas de performance, que serviriam de referência aos incentivos, são prejudicadas (Wilson, 2000). As dificuldades na avaliação dos resultados do policiamento ostensivo são bem conhecidas (U.S. Department of Justice, 1993; Brodeur, 1998). Talvez por conta de todos esses empecilhos, os supervisores recorram à consciência individual.

Este apelo é um recurso em variadas organizações, mas ele tem particular importância quando a função que o agente desempenha não pode ser claramente definida; quando a execução da tarefa é muito dependente dos imperativos da situação; quando se fica à mercê da iniciativa do agente, porque ele pode selecionar os eventos que merecem sua atenção; quando o processo de trabalho é mais importante do que o produto; e, sobretudo, quando os princípios e os valores individuais e de grupo jogam papel relevante na execução do ofício, pois os policiais lidam com assuntos que agridem a ordem moral, e o modo como tratar os acusados envolve a apreciação subjetiva orientada pelos valores dos burocratas das esquinas. Talvez por causa disso o apelo à virtude do agente da linha de frente torne-se essencial e a questão de sua regulação seja tão complexa.

\section{Conclusão}

O poder discricionário dos operadores que atuam nos guichês, nas enfermarias, nas salas de aula e nas ruas é decisivo na execução das políticas públicas. Os recursos oferecidos pela organização estão em geral aquém dos necessários para o bom desempenho das tarefas e as regras formais não dão conta de todos os casos concretos, o que exige a intervenção discricionária dos atores do baixo escalão para que a agência funcione, distribua os bens e preste os serviços, ou seja, esta discricionariedade é condição necessária para que a política pública 
seja concretizada. A questão que se põe é a de como estabelecer os limites dela, a fim de que a accountability e a responsiveness sejam asseguradas.

O exame das condições sob as quais a discrição é exercida e dos fatores que a influenciam pode ajudar a informar a discussão de sua regulação. No caso das burocracias do nível da rua, as perguntas que mais importam são: em que extensão elas são atenciosas com as demandas e denúncias iniciadas pelos indivíduos nos contatos do dia a dia; se elas são mais sensíveis a certos tipos de solicitações e a certos públicos-alvo; que papel os fatores como a carga de trabalho e os recursos concretos desempenham na responsiveness.

Todas essas questões são empíricas, e as soluções produzidas a partir das respostas serão difíceis de ser generalizadas. Os mecanismos que contribuírem para aumentar a responsiveness nas organizações em que o processo de trabalho pode ser acompanhado e/ou o produto final pode ser mensurado dificilmente serão transpostos sem dificuldades para as agências onde o processo de trabalho não pode ser seguido e é mais relevante do que o produto.

Há também a accountability, que no debate público é muitas vezes apresentada de modo abstrato. A accountability não é abstrata, é-se accountable perante alguém. Quanto mais definida for a autoridade a quem prestar contas e mais claros forem seus poderes reais, mais resultados positivos podem ser obtidos no controle. A multiplicidade de atores a quem prestar satisfação tem impacto negativo na regulação de condutas. Mas, quando se trata de implementação de políticas públicas, há um problema crônico: não é incomum o envolvimento de mais de uma agência. A governança pode ser importante para ampliar a participação do cidadão, mas ela dilui a accountability, por conta dos objetivos e interesses conflitantes dos indivíduos, grupos e organizações nela envolvidos, criando obstáculos à regulação dos atores. Como apresentado pela literatura, a transposição da accountability governamental para a accountability da governança não resolve os problemas introduzidos pela discrição, como não o fazem também outras variações de accountability: profissional; participativa (Hupe e Hill, 2007).

Se a organização, sobretudo por meio de seus gerentes na ponta do sistema, pode agir sobre a discricionariedade dos agentes, essa ação encontra limites nos interesses individuais, profissionais e de grupo dos servidores da base, e não será suficiente declará-los "espúrios" para que eles desapareçam; eles resistirão e sobreviverão. O desafio maior permanece sendo a produção de mecanismos de regulação que não apenas punam os desviantes, mas que detenham a conduta indevida, sem que inibam o poder de iniciativa do ator, ou seja, sem que o desestimulem a agir de acordo com seu próprio juízo. Caso contrário, os impasses gerados pelos conflitos entre accountability, responsiveness e equidade e pela crônica escassez de recursos ficarão sem as soluções empíricas dadas pelo burocrata da linha de frente, e os cidadãos serão os prejudicados.

\section{Referências}

BALLA, Steven. Political and organizational determinants of bureaucratic responsiveness. American Political Research, v. 28, p. 163-193, 2000. 
BITTNER, Egon. Aspectos do trabalho policial. São Paulo: Edusp, 2003.

BOUCHARD, Geneviève; CARROLL, Barbara. Policy-making and administrative discretion. Canadian Public Administration, v. 45, n. 2, p. 239-257, 2002.

BREWER, Gene. In the eye of the storm: frontline supervisors and federal agency performance. Journal of Public Administration Research and Theory, v. 15, p. 505-527, 2005.

BRODEUR, Jean-Paul. How recognize good policing. California: Sage, 1998.

CLARK, Peter; WILSON, James. Q. Incentives systems: a theory of organizations. Administrative Science Quarterly, v. VI, p. 219-266, 1961.

CROZIER, Michel. Le phénomène bureaucratique. Paris: Éditions du Seuil, 1963.

CROZIER, Michel; FRIEDBERG, Erhard. L'acteur et le systéme. Paris: Éditions du Seuil, 1977.

DE LEON, Peter. The missing link revisited: contemporary implementation research. Politics Studies Review, v. 3/4, p. 311-338, 1999.

DOWNS, Anthony. Inside bureaucracy. Illinois: Waveland Press, 1967.

EVANS, Tony. Professionals, managers and discretion: critiquing street-level bureaucracy. British Journal of Social Workers, v. 41, p. 368-386, 2011.

FRIEDBERG, Erhard. O poder e a regra. Lisboa: Instituto Piaget, 1993.

FURLONG, Scott. Political influence on the bureaucracy: the bureaucracy speaks. Journal of Public Administration Research and Theory, v. 8, n. 1, p. 39-65, 1998.

HIIL, Heather. Understanding implementation: street-level bureaucrats' resources for reform. Journal of Public Administration Research and Theory, v. 13, n. 3, p. 265-282, 2003.

HUPE, Peter; HILL, Michael. Street-level bureaucracy and public accountability. Public Administration, v. 85, n. 2, p. 279-299, 2007.

KLOCKARS, Carl. The dirty Harry problem. In: KLOCKARS, Carl; MASTROFSKI, Stephen (Ed.). Thinking about the police. Massachusets: McGraw Hill, 1991b. p. 413-423.

KLOCKARS, Carl. The rhetoric of community policing. In: KLOCKARS, Carl; MASTROFSKI, Stephen (Ed.). Thinking about the police. Massachusets: McGraw Hill, 1991a. p. 530-542.

LIPSKY, Michael. Street-level bureaucracy: dilemmas of the individual in public services. Nova York: Russel Sage Foundation, 1980.

LOUBET DEL BAYLE, Jean-Louis. La police dans le systéme politique. Revue Française de Science Politique, v. 31, n. 3, p. 509-534, 1981.

MANNING, Peter. Police work. Illinois: Waveland Press, 1997.

MARCH, James; SIMON, Herbert. Organitazions. Massachussets: Blackwell Publishers, 1993 [1958]. 
MATLAND, Richard. Synthesizing the implementation literature. Journal of Public Administration Research and Theory, v. 5, n. 2, p. 145-174, 1995.

MAY, Peter; WINTER, Soren. Politicians, managers, and street-level bureaucrats. Journal of Public Administration Research and Theory, v. 19, p. 453-476, 2007.

MAY, Peter; WOOD, Richard. At the regulatory front lines. Journal of Public Administration Research and Theory, v. 13, n. 2, p. 117-139, 2003.

MAYNARD-MOOD, Steven; MUSHENO, Michael. State agent or citizen agent: two narratives of discretion. Journal of Public Administration Research and Theory, v. 10, n. 2, p. 329-358, 2000.

MECHANIC, David. Sources power of lower participants in complex organizations. Administrative Science Quarterly, v. 7, n. 3, p. 349-364, 1962.

MONJARDET, Dominique. Ce que fait la police. Paris: La Decouverte, 1996.

MUIR, William. Police - streetcorner politicians. Chicago: The University of Chicago Press, 1977.

NICHOLSON-CROTTY, Sean; O'TOOLE JR., Laurence. Public management and organizational performance: the case of law enforcement agencies. Journal of Public Administration Research and Theory, v. 14, n. 1, p. 1-18, 2004.

OLIVEIRA, Antonio. Os fazedores de paz: a polícia cidadã dos oficiais policiais militares da Bahia. Tese (doutorado) — Universidade de São Paulo, São Paulo, 2005.

PANDEY, Sanjav; WRIGHT, Bradley. Connecting the dots in public management. Journal of Public Administration Research and Theory, v. 16, p. 511-532, 2006.

PRESSMAN, Jeffrey; WILDAVSKY, Aaron. Implementation. Berkeley: University of California Press, 1973.

REISS, Albert. The police and the public. New Haven: Yale University Press, 1971.

SELZNICK, Phillip. Foundations of the theory of organizations. American Sociological Review, v. 13, n. 1, p. 25-35, 1948.

SIMON, Herbert. Administrative behavior. Nova York: Free Press, 1997 [1947].

SIMON, Herbert. Organizations and markets. Journal of Economic Perspectives, v, II, p. 25-44, 1991.

SKOLNICK, Jerome; FYFE, James. Above the law: police and the excessive use of force. Nova York: Free Press, 1993.

U. S. DEPARTMENT OF JUSTICE. Performance measures for the criminal justice system. 1993. Disponível em: <http://bjs.ojp.usdoj.gov/content/pub/pdf/pmcjs.pdf>.

VAN METER, Donald; VAN HORN, Carl. The policy implementation process: a conceptual framework. Administration and Society, v. 6, n. 4, p. 445-488, 1975.

WATERMAN, Richard et al. The venues of influence: a new theory of political control of the bureaucracy. Journal of Public Administration Research and Theory, v. 8, n. 1, p. 13-38, 1998. 
WEISBROD, Burton. Rewarding performance that is hard to measure: the private nonprofit sector. Science, v. 244, p. 541-546, 1989.

WILSON, James Q. Bureaucracy. Nova York: Basic Books, 2000 [1989].

WILSON, James Q. The bureaucracy problem. The Public Interest, p. 3-9, 1967.

WOOD, Dan; WATERMAN, Richard. The dynamics of political control of the bureaucracy. American Political Science Review, v. 85, n. 3, p. 801-828, 1991.

Antonio Oliveira é professor adjunto do departamento de Ciência Política da Universidade Federal da Bahia (Ufba).E-mail: asoufba@uol.com.br. 
